ARTICLE

Received 8 Jun 2015 | Accepted 29 Aug 2015 | Published 16 Oct 2015

DOI: $10.1038 /$ ncomms 9505 OPEN

\title{
Structural basis for phosphatidylinositol-phosphate biosynthesis
}

Oliver B. Clarke ${ }^{1, \star}$, David Tomasek $^{2, \star}$, Carla D. Jorge ${ }^{3, \star}$, Meagan Belcher Dufrisne $^{2}$, Minah Kim $^{2}$, Surajit Banerjee ${ }^{4}$, Kanagalaghatta R. Rajashankar ${ }^{4}$, Lawrence Shapiro ${ }^{1}$, Wayne A. Hendrickson ${ }^{1}$, Helena Santos ${ }^{3}$ \& Filippo Mancia ${ }^{2}$

Phosphatidylinositol is critical for intracellular signalling and anchoring of carbohydrates and proteins to outer cellular membranes. The defining step in phosphatidylinositol biosynthesis is catalysed by CDP-alcohol phosphotransferases, transmembrane enzymes that use CDP-diacylglycerol as donor substrate for this reaction, and either inositol in eukaryotes or inositol phosphate in prokaryotes as the acceptor alcohol. Here we report the structures of a related enzyme, the phosphatidylinositol-phosphate synthase from Renibacterium salmoninarum, with and without bound CDP-diacylglycerol to 3.6 and $2.5 \AA$ resolution, respectively. These structures reveal the location of the acceptor site, and the molecular determinants of substrate specificity and catalysis. Functional characterization of the 40\%-identical ortholog from Mycobacterium tuberculosis, a potential target for the development of novel anti-tuberculosis drugs, supports the proposed mechanism of substrate binding and catalysis. This work therefore provides a structural and functional framework to understand the mechanism of phosphatidylinositol-phosphate biosynthesis.

\footnotetext{
${ }^{1}$ Department of Biochemistry and Molecular Biophysics, Columbia University, New York, NY 10032, USA. ${ }^{2}$ Department of Physiology and Cellular Biophysics, Columbia University, New York, NY 10032, USA. ${ }^{3}$ Biology Division, Instituto de Tecnologia Química e Biológica, Universidade Nova de Lisboa, Avenida da República-EAN, 2780-157 Oeiras, Portugal. ${ }^{4}$ NE-CAT and Department of Chemistry and Chemical Biology, Cornell University, Argonne National Laboratory, Argonne, IL 60439, USA. * These authors contributed equally to this work. Correspondence and requests for materials should be addressed to F.M. (email: fm123@cumc.columbia.edu).
} 
n eukaryotes, phosphatidylinositol (PI)-based lipids (phosphoinositides) play important roles in numerous aspects of intracellular signalling and in the anchoring of glycosylphosphatidylinositol-linked proteins to the membrane. In prokaryotes, PI is produced by mycobacteria, as well as some other bacterial genera, where it is required for the biosynthesis of key components of the cell wall. For example, the cell walls of mycobacteria carry complex lipoglycans such as lipomannan and lipoarabinomannan, which are tethered to the membrane via a common PI anchor that constitutes their first building block ${ }^{1}$. In Mycobacterium tuberculosis, these lipids function as important virulence factors and modulators of the host immune response ${ }^{1,2}$.

Eukaryotic PI synthases process myo-inositol and CDPdiacylglycerol (CDP-DAG) to generate PI directly in a single step $^{3}$. In prokaryotes, PI biosynthesis occurs in two steps. In the initial step, phosphatidylinositol-phosphate (PIP) synthases (Fig. 1a) generate PIP using L-myo-inositol-1-phosphate (inositol phosphate) as the acceptor alcohol and CDP-DAG as the donor substrate; subsequently, the terminal phosphate is removed by an as-yet-unidentified phosphatase to yield $\mathrm{PI}^{4}$. A homologous enzyme (archaetidyl-myo-inositol phosphate synthase) has been characterized in archaea, which like the PIP synthases uses inositol phosphate as the acceptor, but requires CDP-archaeol, an isoprene-based ether-linked lipid, as the donor instead of CDP-DAG ${ }^{5}$. Each of these enzymes is a member of the class I CDP-alcohol phosphotransferases (CDP-APs); class II CDP-APs are peripheral membrane proteins of an unrelated fold, and are not involved in PI biosynthesis (class II enzymes will not be discussed here, and we will use the term CDP-APs as referred to class I family members only). All (class I) CDP-APs are integral membrane enzymes that catalyse the transfer of a substituted phosphate group from a CDP-linked donor, CDPDAG for PI and PIP biosynthesis, to an acceptor alcohol to generate a phosphodiester-linked product ${ }^{3,6,7}$.
Two recent structure reports on CDP-APs from Archaeoglobus fulgidus (Af), a protein termed $A f 2299$ and a di-myo-inositolphosphate phosphate synthase (AfDIPP synthase) have offered a first glimpse of the transmembrane (TM) architecture and catalytic machinery of this enzyme family ${ }^{8,9}$. However, neither Af2299 nor AfDIPP synthase process lipids, leaving unanswered the key question of how membrane-embedded substrates are recruited and processed by CDP-APs, to generate glycerophospholipids such as PI and PIP. To shed light on this question at a molecular level, we decided to focus on the PIP synthases for three reasons. First, they are the closest evolutionary relatives to Af2299 and AfDIPP synthase ${ }^{10}$, an advantage for the crystal engineering approach we adopted here and which is described below. Second, PIP synthases bind CDP-DAG as donor substrate, a feature in common with eukaryotic PI and cardiolipin synthases, as well as all prokaryotic CDP-APs involved in glycerophospholipid biosynthesis. Third, they have possible medical relevance, as genetic ablation of mycobacterial PIP synthase is lethal ${ }^{11}$. This, combined with the unique pathway used for PI synthesis in prokaryotes, may position PIP synthase as a potentially attractive future drug target $^{12,13}$.

We have determined the crystal structures of PIP synthase from Renibacterium salmoninarum, in the apo form and with bound CDP-DAG to 2.5 and $3.6 \AA$ resolution, respectively. These structures show how CDP-DAG binds to the enzyme, and reveal the molecular determinants of substrate specificity and catalysis. Functional assays performed on PIP synthase from M. tuberculosis, which is $40 \%$-identical to the ortholog from $R$. salmoninarum, and a potential target for the development of novel anti-tuberculosis drugs, supports the proposed mechanism of substrate binding and catalysis. This work provides both a structural and a functional framework to investigate and understand PIP biosynthesis.

a

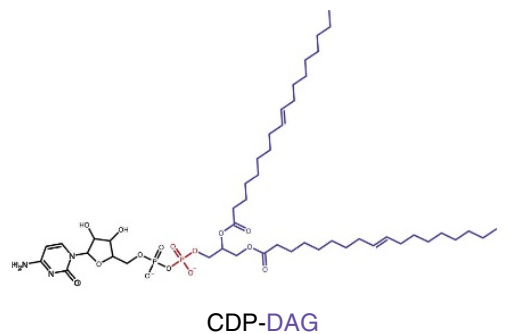

CDP-DAG

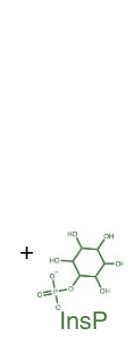

nsP

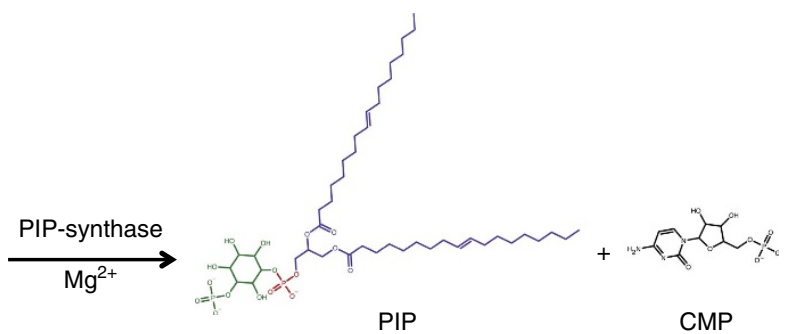

b
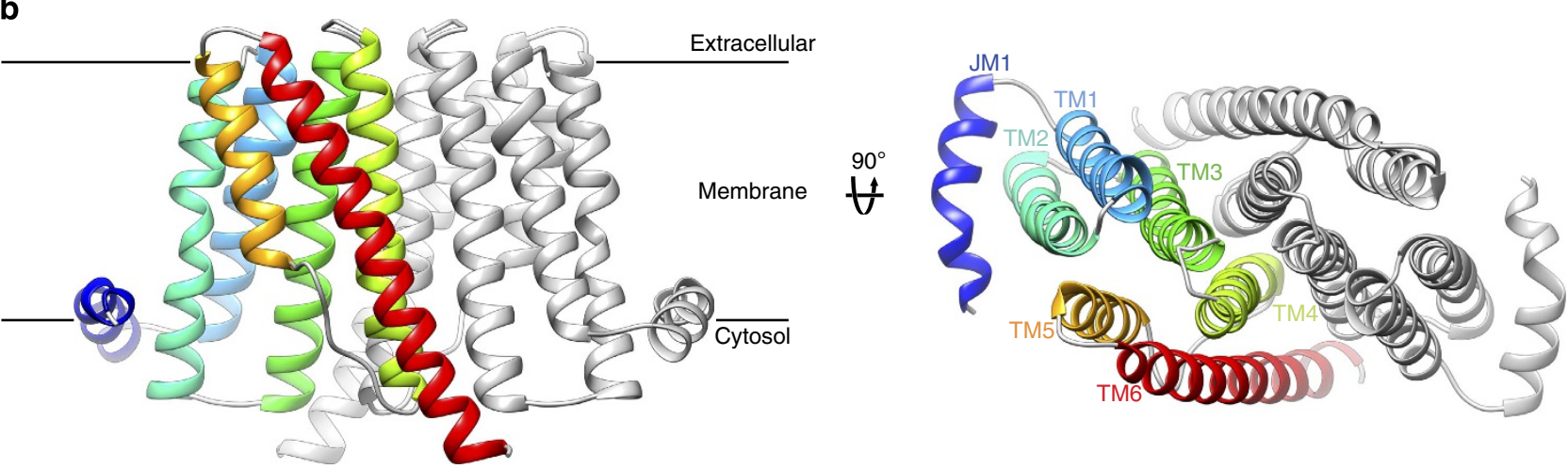

Figure 1 | Transmembrane architecture of a PIP synthase from $\boldsymbol{R}$. salmoninarum. (a) PIP synthases catalyse the transfer of a diacylglycerol-substituted phosphate group (purple/red) from the CDP-DAG donor to the inositol phosphate acceptor (green), generating PIP and CMP. (b) Structure of the RsPIPS- $\triangle 6 \mathrm{~N}$ homodimer in ribbon representation viewed from two orthogonal orientations (in the plane of the membrane on the left; towards the cytosol down the dimer axis on the right). One protomer is coloured grey, and the helices of the other are depicted in spectral colouring, from blue (JM1) to red (TM6). The Af2299 extramembrane domain used to facilitate crystallization is not shown here. 


\section{Results}

Crystal engineering and structure determination. Initial attempts to express and crystallize several mycobacterial PIP synthases and close bacterial homologues were unsuccessful. We rationalized that this might be due, at least in part, to the lack of a crystal contact forming soluble domain. Unlike most other CDP-APs, both Af2299 and AfDIPP synthase have an N-terminal cytosolic cytidylyltransferase-like domain ${ }^{14,15}$, which provided the essential contacts in the crystal lattice between layers of molecules ${ }^{8}$. We reasoned that the Af2299 extramembrane domain might be able to improve the performance in crystallization experiments of other CDP-APs. To test this hypothesis, we generated chimeric constructs by fusing the Af2299 cytosolic domain to the $\mathrm{N}$-terminus of 14 different PIP synthases. We also introduced mutations at six positions in all 14 PIP-synthase sequences to mimic the interface between soluble and TM domains observed in the structure of Af2299 (Supplementary Fig. 1). Attachment of this domain led to a significant increase in expression levels for all the constructs tested, and proteins from several species of mycobacteria and bacteria yielded crystals by the lipidic cubic phase technique ${ }^{16}$. We determined the structure of a chimeric construct of PIP synthase from $R$. salmoninarum (RsPIPS) - the causative agent for bacterial kidney disease in salmonids, a major threat to these species worldwide ${ }^{17}$-in which the first six residues of the RsPIPS sequence were omitted (RsPIPS- $\Delta 6 \mathrm{~N}$; Supplementary Fig. 1). Crystals of RsPIPS- $\Delta 6 \mathrm{~N}$ diffracted X-rays to $2.5 \AA$ resolution, and the structure was solved by molecular replacement using the cytidylyltransferase-like domain of Af2299 as a search model (Table 1). Subsequently, we determined the structure of a construct containing the complete RsPIPS sequence (absent the initiating methionine; $R s$ PIPS-FL) in complex with CDP-DAG at $3.6 \AA$ resolution, again by molecular replacement, in this instance using $R s P I P S-\Delta 6 \mathrm{~N}$ as search model (Table 1 and Supplementary Fig. 1).

In both structures, the relative disposition of the transmembrane and soluble domains is very similar to that observed in the structure of $A f 2299$. Of the six mutations introduced at the RsPIPS-Af2299 interface, two appear particularly important in limiting flexibility between the two domains. L75 and F77, which are both located in the loop between TM2 and TM3, are buried in hydrophobic pockets on the surface of the cytidylyltransferaselike domain, replicating the interactions observed in the crystal structure of Af2299 (Supplementary Fig. 1).

Transmembrane architecture and active site in $R s P I P S-\Delta 6 \mathrm{~N}$. RsPIPS adopts a homodimeric architecture similar to those previously observed in Af2299 and AfDIPP synthase (Fig. 1b and Supplementary Fig. 2), with each protomer possessing six TM helices surrounding a large polar cavity. Sequence alignment with eukaryotic CDP-APs that process a lipidic acceptor substrate, such as choline/ethanolamine phosphotransferase (CEPT1; Supplementary Fig. 3) suggests that these eukaryotic enzymes may possess an additional three to four TM helices at the $\mathrm{C}$ terminus, perhaps serving as an additional TM module to accommodate the bulkier, hydrophobic acceptor. In RsPIPS, the central polar cavity is located at the cytosolic boundary of the membrane, and contains three distinct regions, which together form the active site (Fig. 2a). The nucleotide-binding site is delineated by TMs 1,2 and 3 , and is characterized by a signature sequence featuring eight absolutely conserved residues $\left(D_{1} x x D_{2} G_{1} x x A R \ldots G_{2} x_{x x D} x_{3 x D}\right)$ (ref. 18), five of which are located on TM2 and three on TM3. As observed previously ${ }^{8}$, the first three of the conserved aspartate side chains coordinate a metal, and $\mathrm{D}_{4}$ likely acts as the catalytic base. The four other signature amino acids either provide structural flexibility or line the binding site that accommodates the pyrimidine ring of the $\mathrm{CDP}^{8}$.
Proximal to the nucleotide-binding site, and within the membrane-spanning region is a pocket wedged between TMs 4, 5 and 6, which probably represents the inositol phosphate acceptor-binding cavity (Fig. 2). Several conserved residues line this cavity, including two arginine residues (R153 and R191) that in the structure of RsPIPS- $\Delta 6 \mathrm{~N}$ coordinate a $\mathrm{SO}_{4}^{2-}$ ion present at high concentration in the crystallization solution. R153 and R191 are absolutely conserved amongst all PIP synthases, but not in eukaryotic PI synthases. We hypothesize that these residues coordinate the phosphate of inositol phosphate, a moiety unique to PIP synthases.

Directly above the nucleotide-binding site, we observed a gap between JM1 and TM2, creating a hydrophobic groove that is open to the membrane. In contrast, the structures of Af2299 and AfDIPP synthase displayed a small, hydrophilic pocket in this region, which in the case of Af2299 was shown to accommodate the glycerol moiety of the CDP-glycerol donor. The difference in the nature of the donor substrate, CDP-DAG for RsPIPS and CDP-glycerol for Af2299 is most likely responsible for the differences observed in the architecture of the donor-substituent site in these two enzymes.

Structure of RsPIPS in complex with CDP-DAG. We initially engineered RsPIPS chimeric constructs with alternative junctions to the N-terminal domain (Supplementary Fig. 1), and crystals were obtained of two of these, RsPIPS- $\Delta 6 \mathrm{~N}$ and RsPIPS-FL. The crystals of RsPIPS- $\Delta 6 \mathrm{~N}$ diffracted well in the apo-state $(2.5 \AA)$, but attempts to obtain co-crystal structures with CDP-DAG were unsuccessful. In contrast, although crystals of RsPIPS-FL only diffracted to lower resolution $(3.6 \AA)$, a structure of the complex with CDP-DAG was obtained readily. The structure of the complex of CDP-DAG bound to RsPIPS-FL revealed strong density for CDP, with the nucleotide ring wedged between TMs 2 and 3 , and the diphosphate moiety coordinated by a bound magnesium ion that also interacts with conserved aspartate residues of the CDP-AP signature sequence (Fig. 2b). In all four protomers in the asymmetric unit, density was also observed for the acyl chains of the CDP-DAG, which lie against the TM region in a groove formed by JM1, TM2 and TM5 (Fig. 3, Supplementary Fig. 4 and Supplementary Movie 1). This groove is entirely absent in the two previous structures of CDP-APs, which have a small, hydrophilic pocket in this location, consistent with their preference for soluble donor moieties such as CDP-glycerol and CDP-inositol (Supplementary Fig. 1i).

Functional validation of crystallization constructs. Functional characterization of RsPIPS-FL, performed by measuring incorporation of $\mathrm{L}-$ myo- $\left[{ }^{14} \mathrm{C}\right]$ inositol-1-phosphate into membranes derived from RsPIPS-FL-expressing Escherichia coli cells, revealed that although this enzyme from $R$. salmoninarum exhibits significant $\mathrm{Mg}^{2+}$-dependent PIP-synthase activity (Supplementary Fig. 1j), we judged the activity level to be too low to provide the basis for a reliable assay system. By contrast, equivalent constructs of the close PIP-synthase homolog from M. tuberculosis (MtPIPS; $40 \%$ identity to RsPIPS) showed robust specific activity (Supplementary Fig. 1j). We therefore used MtPIPS, which has high homology to RsPIPS in its active site region (Supplementary Fig. 5), as an assay system for structure-based functional characterization of PIP synthases.

Functional characterization of the chimeric $M t$ PIPS proteins revealed that the activity of $M t$ PIPS- $\Delta 6 \mathrm{~N}$ was substantially lower than that of MtPIPS-FL (Supplementary Fig. 1j). We hypothesize that this diminished activity of $M t$ PIPS- $\Delta 6 \mathrm{~N}$ is due to compromised binding of CDP-DAG, as JM1 is truncated and distorted in RsPIPS- $\Delta 6 \mathrm{~N}$, potentially interfering with CDP-DAG 


\section{Table 1 | Data collection and refinement statistics.}

Total reflections

Unique reflections

Multiplicity

Completeness (\%)

Mean $I / \operatorname{sigma}(I)$

Wilson $B$-factor

$R_{\text {merge }}$

$R_{\text {meas }}$

CC ( $1 / 2)$

Resolution where I/sigma(I) drops below 2.0 (overall)

Resolution where I/sigma(I) drops below 2.0 (along $h$ )

Resolution where I/sigma(I) drops below 2.0 (along $k$ )

Resolution where $I /$ sigma(I) drops below 2.0 (along I)

Resolution where CC(1/2) drops below 0.5 (overall)

Resolution where CC $(1 / 2)$ drops below 0.5 (along $h$ )

Resolution where CC(1/2) drops below 0.5 (along $k$ )

Resolution where CC $(1 / 2)$ drops below 0.5 (along I)

Reflections used in refinement

Reflections used for $R_{\text {free }}$

$R_{\text {work }}$

$R_{\text {free }}$

Number of atoms (all non-hydrogen)

Number of atoms (protein)

Number of atoms (ligands)

Protein residues

RMS (bonds)

RMS (angles)

Ramachandran favoured (\%)

Ramachandran allowed (\%)

Ramachandran outliers (\%)

Rotamer outliers (\%)

Clashscore

Average $B$-factor (all atoms)

Average $B$-factor (protein)

Average $B$-factor (ligands)

Average $B$-factor (solvent)

Number of TLS groups
RsPIPS- $\Delta \mathbf{6 N}$

RsPIPS-FL

0.979

$103.92-2.50(2.60-2.50)$

$14.92-2.502$ (2.591-2.502)

P $22_{1} 2,2$

$a=48.63$

$b=94.069$

$c=103.92$

$320,975(21,993)$

$16,784(1,453)$

$19.0(13.6)$

$98.2(84.5)$

$9.9(1.7)$

43.74

$0.267(1.654)$

$0.281(1.775)$

0.999 (0.636)

2.59

2.50

3.25

2.61

2.50

2.50

3.34

2.59

$16,891(1,453)$

$824(58)$

$0.2284(0.3326)$

$0.2520(0.3627)$

2,952

2,586

333

338

0.003

0.72

98

2

0

1.8

2.87

70.55

70.89

69.59

53.66

2
0.979

$167.3-3.613(3.97-3.61)$

$167.3-3.613$ (3.742-3.613)

$$
\mathrm{P} 2{ }_{1}
$$

$a=89.00$

$b=62.49$

$c=169.76$

$\beta=99.77$

$78,622(18,367)$

$21,268(1,996)$

$3.7(3.8)$

$98.9(97.9)$

$5.0(1.4)$

79.46

$0.252(0.930)$

$0.294(1.087)$

$0.991(0.616)$

3.89

4.09

4.09

3.62

3.62

3.84

4.05

3.62

$21,268(1,986)$

1,043 (117)

$0.2801(0.3918)$

$0.2997(0.4246)$

10,845

10,350

495

1,358

0.004

1.07

97

1.9

0.1

1.7

8.53

76.53

77.17

63.13

Statistics for the highest-resolution shell are shown in parentheses; RMS, root mean square; TLS, Translation-Libration-Screw.

binding (Supplementary Fig. 1i). This could provide an explanation as to why we were unable to obtain the structure of RsPIPS- $\Delta 6 \mathrm{~N}$ in complex with its cognate lipid substrate. The length of the linker appears to be the primary cause of the reduced activity of the $\Delta 6 \mathrm{~N}$ construct, not the addition of the Af2299 domain, nor the interface mutations. Indeed, the activity of $M t$ PIPS-FL is comparable to the activity of $M t$ PIPS constructs lacking the extramembrane domain and interface mutations (Supplementary Fig. 1j). All proteins tested expressed to comparable levels. Kinetic characterization of the construct lacking the extramembrane domain and interface mutations showed that the $K_{\mathrm{M}}$ for inositol phosphate is somewhat lower for the engineered construct $(122$ versus $243 \mu \mathrm{M})$, while the $K_{\mathrm{M}}$ for CDP-DAG is somewhat higher (238 versus $60 \mu \mathrm{M}$; Supplementary Fig. 6a-d). Importantly, the $V_{\max }$ for the engineered construct is comparable to that for the unmodified protein (22 versus $32 \mathrm{nmol}$ PIP per min per mg protein; Supplementary Fig. 6a-d). These data suggest that our addition of a crystallization chaperone fusion combined with engineering of the interface between the two domains, prerequisites for successful crystallization and structure determination, did not substantially impact the capability of the enzyme to function as compared with the wild-type (WT) protein.

Functional characterization of PIP synthase. We selected mutants expected to have compromised substrate binding or catalytic activity based on residue conservation and based on our structures of RsPIPS. These mutations are displayed on a homology model of MtPIPS (Fig. 4a), the enzyme used in our functional assay. All mutants analysed were expressed at levels comparable to WT MtPIPS-FL. Mutation to alanine in MtPIPS of the two arginine residues (R155 and R195) that bind to $\mathrm{SO}_{4}^{2-}$ in the RsPIPS structure (R153 and R191) led to severely compromised activity (Fig. 4b), consistent with disruption of the inositol phosphate-binding site. Both $\mathrm{PO}_{4}^{2-}$ and $\mathrm{SO}_{4}^{2-}$ inhibit activity at 

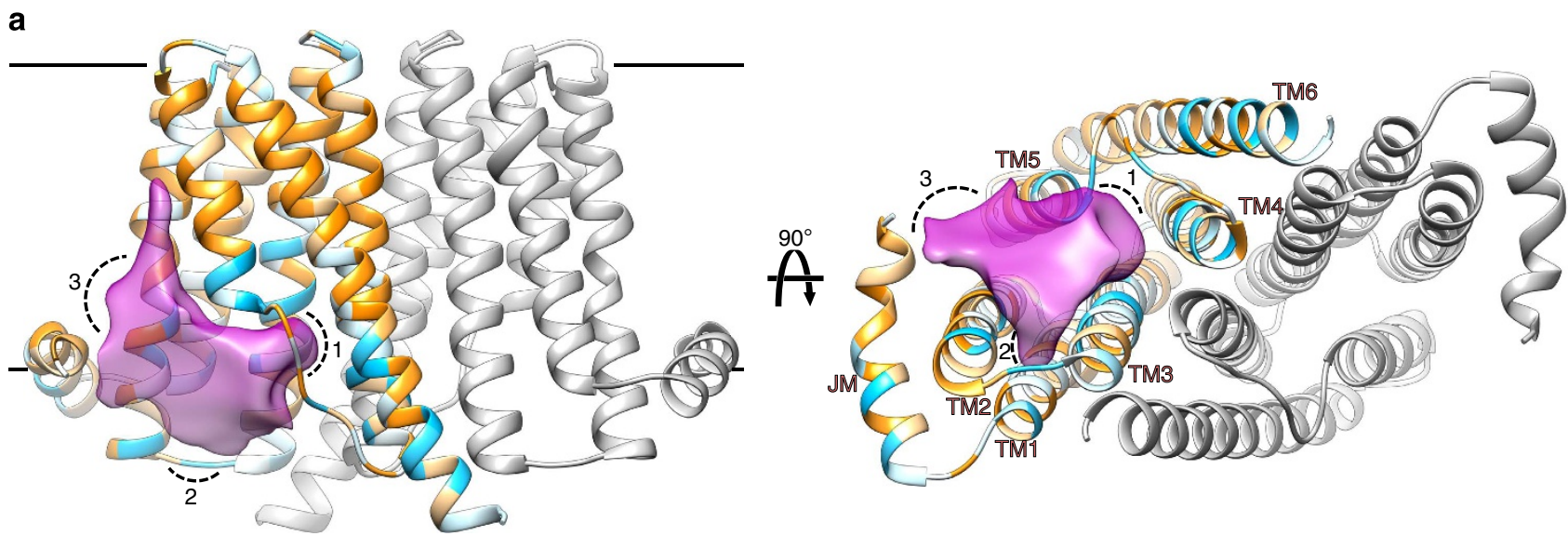

b

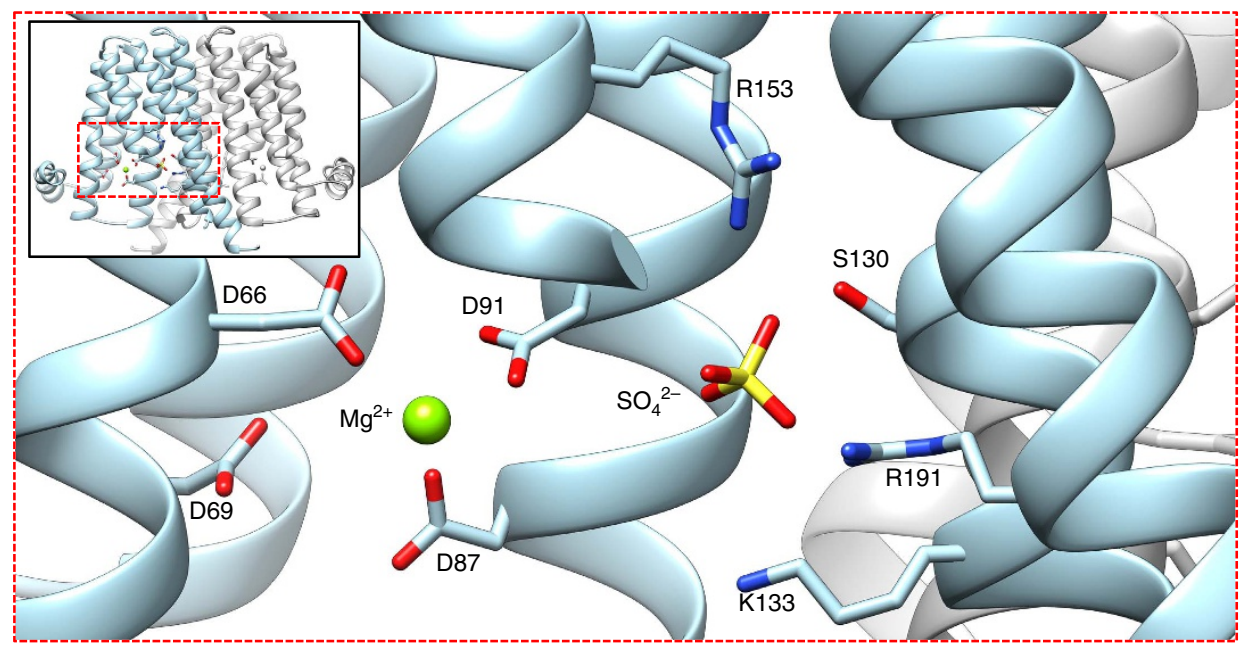

Figure 2 | A large interfacial cavity contains the active site of RsPIPS. (a) The structure of RsPIPS- $\Delta 6 \mathrm{~N}$ is shown in ribbon representation, with one protomer coloured grey and the other coloured by the Kyte-Doolitle hydrophobicity scale ${ }^{34}$, from -4.5 (most polar, light blue) to 4.5 (most hydrophobic, orange). Two orthogonal representations are shown, on the left is a view in the plane of the membrane and on the right is a view from the cytosol along the dimer axis. A transparent purple surface (calculated using the $3 \mathrm{~V} \mathrm{server}{ }^{35}$ ) delineates the borders of the interfacial cavity, which contains three subregions as follows: 1, the inositol phosphate acceptor-binding pocket; 2, the nucleotide-binding pocket between TM2 and TM3; and 3, a hydrophobic groove between TM2 and JM1. (b) Detail of the active site viewed in the plane of the membrane, with side chains that contact the bound $\mathrm{Mg}^{2+}$ and $\mathrm{SO}_{4}^{2-}$ ions labelled and depicted in stick representation.

concentrations well below those used for crystallization (Fig. 4c), consistent with competition between binding of $\mathrm{SO}_{4}^{2-}$ and the phosphate group of inositol phosphate. More subtle substitutions (R/Q) at the same positions (R155 and R195) also resulted in substantial reduction in enzymatic activity (Fig. 4b). Kinetic characterization of inositol phosphate and CDP-DAG-dependent activity of R195Q (Fig. 4d and Supplementary Fig. 6), which retains $\sim 40 \%$ of WT activity, demonstrated that the mutation had only a mild effect on the $K_{\mathrm{M}}$ for CDP-DAG $(236 \mu \mathrm{M}$ for WT; $329 \mu \mathrm{M}$ for R195Q), while severely impairing $K_{\mathrm{M}}$ for inositol phosphate $(122 \mu \mathrm{M}$ for WT; $1,208 \mu \mathrm{M}$ for R195Q). Comparison of WT and R195A proteins extracted and purified from isolated membranes with a non-ionic detergent showed that both proteins are membrane inserted and have the same elution profile on sizeexclusion chromatography (SEC), strongly suggesting that this point mutation does not compromise folding (Supplementary Fig. 7). Direct single-point measurements of L-myo- $\left[{ }^{14} \mathrm{C}\right]$ inositol1-phosphate binding to liposome-incorporated R195Q, WT and D93N $\left(\mathrm{D}_{4}\right) M t$ PIPS-FL proteins were carried out to differentiate the direct effects of these mutations on inositol phosphate affinity from other mechanisms by which catalysis could be impaired (Fig. 4e). These assays were carried out in the presence and absence of CDP-DAG. Intriguingly, inositol phosphate binding was strictly CDP-DAG dependent (Fig. 4e). Determination of the fraction of $\left[{ }^{14} \mathrm{C}\right] \mathrm{PIP}$ in the liposomes after the binding assay was carried out to assess the catalytic activity of the proteins under these conditions. The only sample exhibiting any detectable level of catalytic activity was the WT construct in the presence of CDPDAG, for which nearly all of the radioactive inositol phosphate above the background level was incorporated in the lipophilic PIP and therefore found in the organic phase $(77.8 \pm 0.6 \mathrm{pmol}$ per assay; \pm indicates standard error of the mean, $n=3)$. The amount of inositol phosphate bound in total was comparable to WT for the D93N mutant, consistent with the role of this residue in catalysis, as opposed to substrate recognition. In contrast, R195Q bound a significantly lower amount of substrate, compatible with its putative function in binding of inositol phosphate. Alanine mutagenesis of a conserved serine (S132) that also interacts with the RsPIPS-bound $\mathrm{SO}_{4}^{2-}$ reduced activity as well, albeit to a lesser extent. Lysine K135 is located such that it may interact with the inositol ring, and the K135A mutation also resulted in a partial loss of activity.

Furthermore, mutation in MtPIPS of P153W, a conserved residue on TM5, which stacks against one of the aliphatic chains 
a
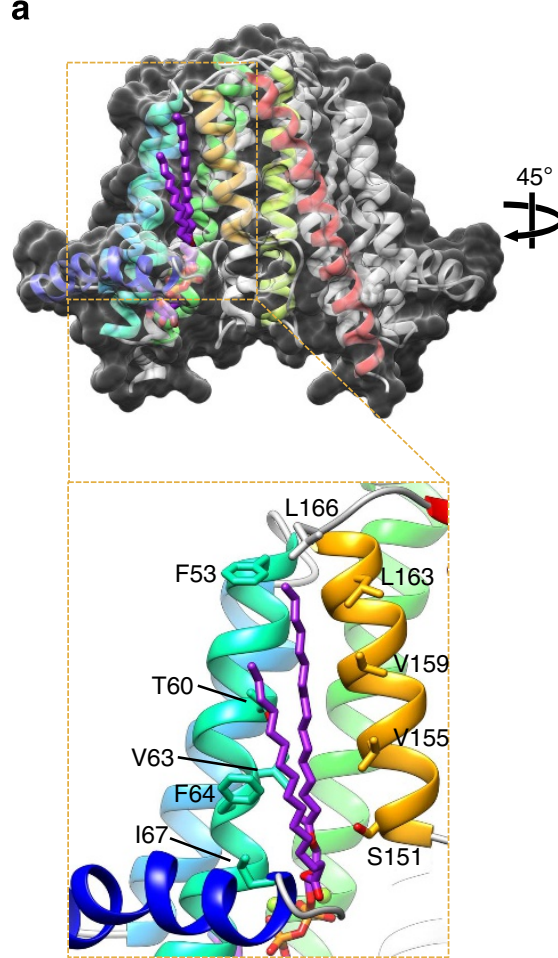

b
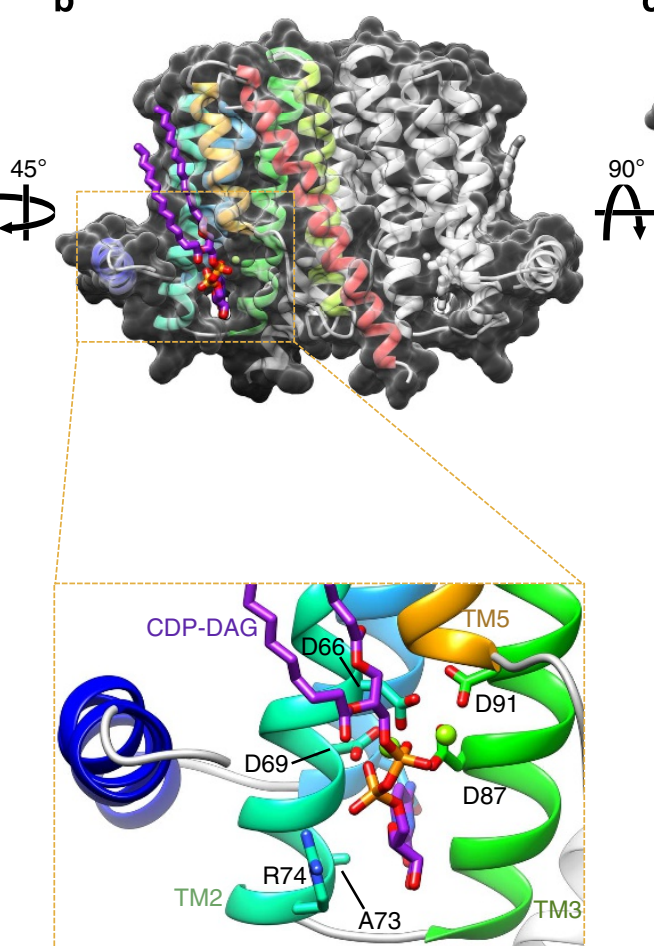

C
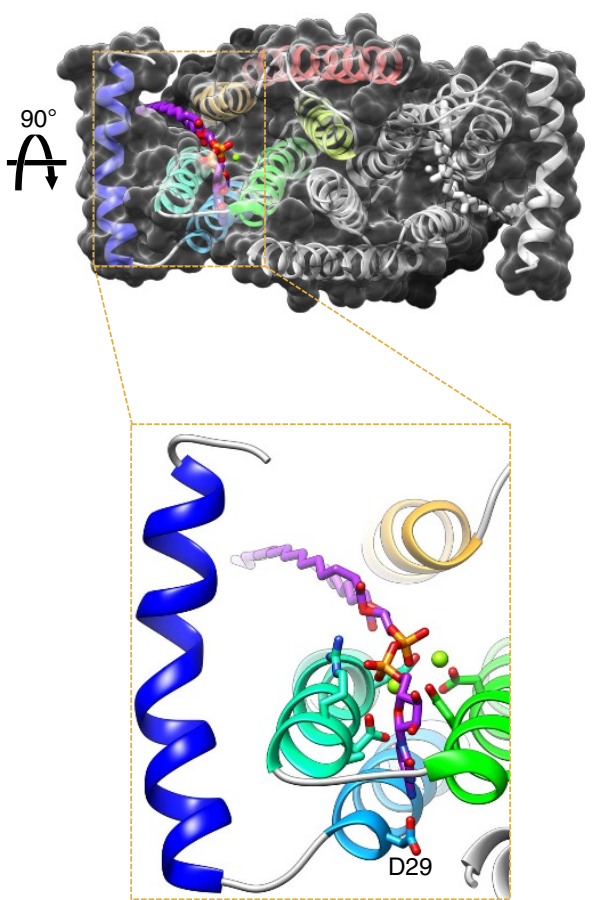

Figure 3 | CDP-DAG binding to RsPIPS-FL. The structure of RsPIPS-FL, depicted in ribbon representation and coloured as per Fig. 1, is shown in three different views (a-c) superimposed on a transparent 'Stromboli black' spacefill model (upper panels), with matching magnified insets of boxed regions below (lower panels). CDP-DAG is depicted in purple and $\mathrm{Mg}^{2+}$ ions in light green. Side chains that contact CDP-DAG or $\mathrm{Mg}^{2+}$ are shown in stick representation.

of CDP-DAG, resulted in nearly complete loss of enzymatic activity, consistent with a loss of CDP-DAG binding due to obstruction of the lipid-binding groove by the larger tryptophan side chain (Fig. 4a,b). In agreement with this hypothesis, substitution of P153 with alanine had minimal effects on activity, while substitution with valine resulted in a partial defect in activity. Kinetic characterization of P153V (Fig. 4d and Supplementary Fig. 6) showed $V_{\max }$ to be substantially decreased, consistent with an effect of this mutation on the catalytic efficiency of the enzyme. Unexpectedly, the $K_{\mathrm{M}}$ for inositol phosphate was increased, whilst the $K_{\mathrm{M}}$ for CDP-DAG was decreased for this mutant, possibly suggestive of a more complex role of P153, critically located at the CDP-DAG entrance to the active site, and two residues in sequence away from R155, one of the two key inositol phosphate-binding residues. Mutation of another residue, L70W, near the groove but oriented away from it, did not affect the activity (Fig. 4a,b), while substitution of the directly adjacent M69, which contacts CDP-DAG from TM2, by tryptophan resulted in severely impaired activity. Substitution with residues similarly sized or smaller than the native methionine did not compromise activity (Fig. 4a,b).

Not surprisingly, mutation of D31, a conserved residue on TM1, which forms a hydrogen bond with the primary amine of $\mathrm{CDP}$, to alanine, also severely compromised activity, but did not completely abolish it (Fig. 4a,b). This partial effect of the D31A mutation is likely due to the fact that most of the residues in the CDP-AP signature sequence participate in binding of the nucleotide, and that T34, present in all CDP-APs as S or T as part of a conserved $\mathrm{P}(\mathrm{D} / \mathrm{N}) \mathrm{xx}(\mathrm{T} / \mathrm{S})$ motif, also binds to the primary amine of the pyrimidine ring, and thus may compensate, at least in part, for the absence of the contribution from D31.

Finally and as expected, even a conservative $\mathrm{D}$ to $\mathrm{N}$ mutation at the site of the putative catalytic base, D93 (the fourth aspartate in the signature sequence) resulted in near complete abrogation of CDP-AP activity (Fig. 4a,b), without compromising substrate binding (Fig. 4e).

\section{Discussion}

The defining step in glycerophospholipid biosynthesis is catalysed by CDP-APs. These constitute a large and diverse family of membrane-embedded enzymes characterized by a signature sequence containing eight absolutely conserved amino acids and 6-10 predicted TM segments. The structure of the CDP-AP RsPIPS reported here exhibits a homodimeric, six-TM architecture similar to those described for Af2299 and AfDIPP synthase $e^{8,9}$. This architecture appears to be conserved amongst all the CDP-AP family members that utilize a soluble acceptor substrate such as inositol or inositol phosphate, irrespective of the nature-hydrophobic or hydrophilic-of the CDP-attached donor (Supplementary Fig. 3). These include all characterized prokaryotic CDP-APs, as well as eukaryotic PI synthases. In contrast, CDP-APs that utilize a lipidic acceptor, such as eukaryotic phosphatidylethanolamine (PE) and phosphatidylcholine (PC) synthases, typically have three or four additional TM helices at the C terminus (Supplementary Fig. 3), which are likely required to accommodate the acyl chains of the bulky hydrophobic acceptor substrate.

Fusion of RsPIPS to a crystallization chaperone derived from the extramembrane domain of Af2299 was instrumental in obtaining diffracting crystals. The employment of crystallization chaperones is a well-established technique for obtaining crystals of otherwise recalcitrant membrane proteins and has enjoyed particularly extensive use in the field of G-protein-coupled receptor crystallography ${ }^{19}$. We believe that the extramembrane domain of Af2299 may prove a valuable addition to the complement of membrane protein crystallization chaperones, 

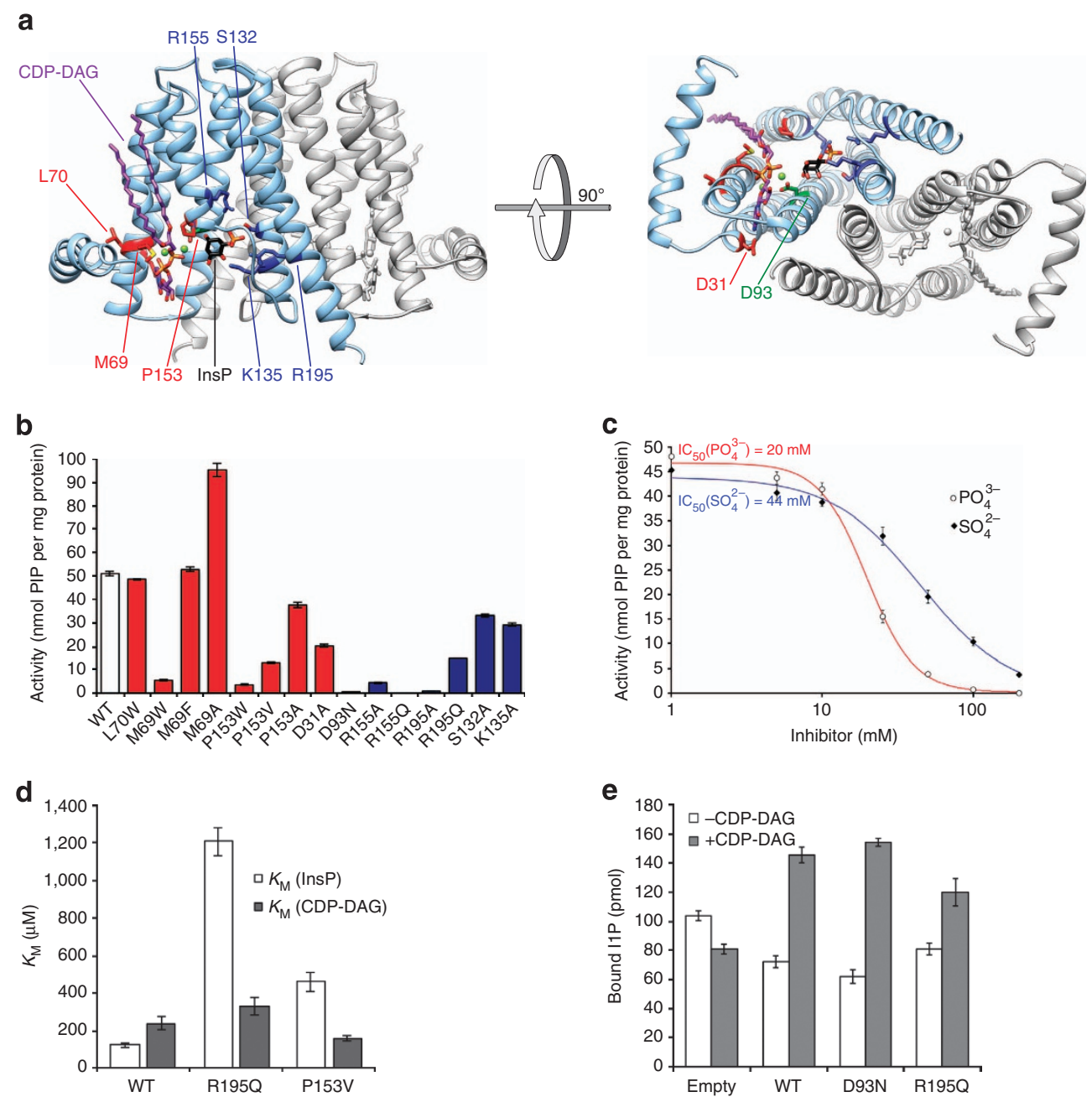

Figure 4 | A homology model of MtPIPS, with functional characterization of selected point mutants. (a) The MtPIPS homology model is shown in ribbon representation with one protomer in grey and the other in light blue, from two views, on the left viewed in the plane of the membrane and on the right from the cytosol, along the dimer axis. The substrates, CDP-DAG (purple) and inositol phosphate (black), are modelled based on the structures of RsPIPS-FL (in complex with CDP-DAG) and RsPIPS- $\Delta 6 \mathrm{~N}$ (with bound $\mathrm{SO}_{4}^{2-}$ ). The homology model was generated using the Phyre2 server ${ }^{36}$, in one-to-one threading mode using the sequence of MtPIPS (Uniprot accession: P9WPG7) as the target and the structure of RsPIPS-FL (with the Af2299 extramembrane domain excised) as the template. Selected residues which are predicted to participate in either inositol phosphate binding (R155, R195, S132, K135), CDP-DAG binding (P153, M69, D31), neither (L70), or catalysis (D93) are shown with side chains in stick representation and coloured as in (b), where the activity of point mutants at these positions for the MtPIPS-FL construct is shown compared to wild-type MtPIPS-FL. (c) $\mathrm{SO}_{4}^{2-}$ (closed diamonds) and PO${ }_{4}^{3-}$ (open circles) inhibit the activity of MtPIPS-FL with half-inhibitory concentrations of 44 and $22 \mathrm{mM}$, respectively. (d) $K_{M}$ of MtPIPS-FL WT, R195Q and P153V for inositol phosphate (InsP; white) and CDP-DAG (grey). InsP, L-myo-inositol-1-phosphate (inositol phosphate). (e) Quantification of bound L-myo- $\left[{ }^{14} \mathrm{C}\right]$ inositol-1-phosphate after incubation of liposomes containing $9 \mu \mathrm{g}$ MtPIPS-FL (WT, D93N, R195Q or empty liposome control) in the presence and absence of $200 \mu \mathrm{M}$ CDP-DAG with $40 \mu \mathrm{M}$ L-myo- $\left[{ }^{14} \mathrm{C}\right]$ inositol-1-phosphate. Measurement errors were quantified as s.e.m. $(n=3)$.

although further studies are necessary to demonstrate the general-purpose utility of this fusion partner.

The structure of RsPIPS confirms the locations of the acceptorand donor-substituent-binding pockets described in the structure of $A f 2299$, and identifies a pair of conserved arginine residues (R153 and R191), as involved in the specific recognition of inositol phosphate. Sequence alignment of RsPIPS with human CEPT1 (Supplementary Fig. 3), a CDP-AP that utilizes a lipid acceptor, shows that an Rxx motif containing R153 aligns to a motif previously identified in CEPT1 as a determinant of acceptor specificity ${ }^{20}$. We suggest that the locations of the acceptor and donor sites are conserved across the entire CDP-AP family, regardless of the identity of the substrates.

A unique feature of the structure of RsPIPS when compared with Af2299 and AfDIPP synthase is the presence of a hydrophobic crevice between JM1, TM2 and TM5 (Fig. 2 and Supplementary Fig. 1i), which in the structure of RsPIPS-FL accommodates the lipid substrate (Fig. 3 and Supplementary Fig. 4). This groove is directly exposed to the bulk lipid, providing a pathway for lateral diffusion of CDP-DAG into the active site. The nucleotide is wedged between TM2 and TM3 in a pocket, which is also lined by TM1. The CDP interacts with residues from the signature sequence on TM2 and TM3. In addition, D29 and T32, part of a conserved $\mathrm{P}(\mathrm{D} / \mathrm{N}) \mathrm{xx}(\mathrm{T} / \mathrm{S})$ motif at the start of TM1, form hydrogen bonds with polar substituents of the pyrimidine ring. Given the absolute conservation of residues lining the nucleotide-binding pocket, we anticipate this mode of binding will be universally conserved.

PI is an essential lipid for mycobacteria, providing the anchor and first building block of major constituents of their cell wall ${ }^{1}$. 
Genetic ablation of PIP synthase in Mycobacterium smegmatis leads to a loss of cell viability ${ }^{11}$. This observation, combined with the unique substrate requirements of MtPIPS, positions this enzyme as a plausible target for the development of novel antituberculosis therapeutics. The structure of RsPIPS provides a high-homology model for MtPIPS ( $40 \%$ identity; Supplementary Fig. 5). We opted to perform experiments aimed at functional characterization of PIP synthase on MtPIPS, due to its higher intrinsic medical interest and the low specific activity of the native RsPIPS enzyme (Supplementary Fig. 1j). The conserved pocket that accommodates the inositol phosphate acceptor provides a potentially attractive site for future structure-based drug design for two reasons. First, inositol phosphate is not recognized by eukaryotic CDP-APs. Second, the affinity of MtPIPS for inositol phosphate is relatively low (Fig. 4d), making displacement by a putative inhibitor more feasible, at least theoretically. Mutation of either of the two conserved arginine residues (R155 and R195) in this pocket resulted in gravely impaired enzymatic activity. We hypothesize that these two residues are responsible for binding of the phosphate of inositol phosphate. Interestingly, although mutation of R195 to a glutamine resulted in severely compromised activity and a increased $K_{\mathrm{M}}$ for inositol phosphate, the binding of inositol phosphate to liposome-incorporated R195Q was reduced only to a moderate degree (Fig. 4e), suggesting R195 may play an additional role in the reaction mechanism beyond its contribution to inositol phosphate affinity, potentially in positioning this substrate appropriately for catalysis. Mutation of residues that line the diacylglycerolbinding groove on either TM2 or TM5 to bulky tryptophans also compromised enzymatic activity of MtPIPS, presumably by obstructing the groove that accommodates the acyl chains of CDP-DAG. We suggest that similar mutations in an ancestral lipid-processing CDP-AP may have contributed to the evolution of polar-osmolyte generating CDP-APs ${ }^{10}$, like AfDIPP synthase, providing a plausible explanation for the existence of an integral membrane enzyme that processes exclusively soluble products and substrates.

Finally, measurements of the binding of inositol phosphate to liposomes containing incorporated MtPIPS-FL (WT and D93N) in the presence and absence of CDP-DAG showed that binding of inositol phosphate is strictly CDP-DAG dependent, and that the D93N mutation, while it almost completely abrogated activity of the enzyme, does not substantially impact substrate affinity (Fig. 4e). The observation that CDP-DAG binding is a prerequisite for inositol phosphate binding (and hence catalysis) implies that MtPIPS follows a sequential ordered bi-bi reaction mechanism in which CDP-DAG binds first, followed by inositol phosphate, and the likely formation of a reactive phosphoryl intermediate through the action of an aspartate residue $\left(\mathrm{D}_{4}\right.$ in the signature sequence) acting as a catalytic base, in this case D93. This is consistent with mechanisms described previously for several other members of the family $7,21-23$.

\footnotetext{
Methods

Target identification and cloning. CDP-alcohol phosphotransferases with predicted involvement in PIP synthesis were identified from 14 prokaryotic organisms by homology to a template of known function. Six mutations were introduced into each one (Supplementary Fig. 1) to replicate the interface between the cytosolic and TM domains observed in the structure of Af2299, and the corresponding genes were synthesized (GenScript). Genes not bearing the mutations at the interface were PCR amplified from the matching genomes. The Uniprot IDs and species of the sequences identified were as follows: 1: Q9F7Y9, M. smegmatis; 2: G6X547, Mycobacterium abscessus; 3: K0UMF3, Mycobacterium fortuitum subsp. fortuitum; 4: R4N892, Mycobacterium avium subsp. paratuberculosis; 5: D5MTP6, Mycobacterium marinum; 6: Q7D6W6, M. tuberculosis; 7: H6MZX4, Gordonia polyisoprenivorans; 8: Q0S1E0, Rhodococcus sp. (strain RHA1); 9: Q5YTD3, Nocardia farcinica; 10: D9UX52, Streptomyces sp. AA4; 11: F5XFI2, Microlunatus phosphovorus; 12: K9B2F1, Brevibacterium casei; 13: A9WSF5,
}

R. salmoninarum; and 14: K1ENZ2, Janibacter hoylei. PCR was used to amplify the bacterial expression vector pMCSG7 encoding Af2299 (with an N-terminal decahistidine tag and a Tobacco Etch Virus (TEV) protease cleavage site), excluding the portion of the gene not encoding the N-terminal soluble domain. Gibson assembly ${ }^{24}$ was used to fuse the genes encoding PIP synthases to the linear fragment of the pMCSG7-Af2299 vector. All point mutants of MtPIPS were generated using the QuikChange site-directed mutagenesis kit (Agilent). Sequences of all primers used for cloning and mutagenesis are provided in Supplementary Table 1 .

Membrane isolation and protein expression and purification. For protein overexpression, plasmids encoding PIP synthases, generated as described above, were transformed into BL21 (DE3) pLysS E. coli competent cells. Transformed cells were used to inoculate a starter culture $(8 \mathrm{~mL})$ of $2 \mathrm{xYT}$ medium supplemented with $100 \mu \mathrm{g} \mathrm{ml}^{-1}$ ampicillin and $50 \mu \mathrm{g} \mathrm{ml}^{-1}$ chloramphenicol. This culture was grown at $37^{\circ} \mathrm{C}$ overnight while shaking ( 240 r.p.m.). The next day, the starter culture was used to inoculate $800 \mathrm{ml}$ of $2 \mathrm{xYT}$ medium supplemented with $100 \mu \mathrm{g} \mathrm{ml}^{-1}$ ampicillin and $50 \mu \mathrm{g} \mathrm{ml}-1$ chloramphenicol. Cultures were again grown at $37^{\circ} \mathrm{C}$ while shaking ( 240 r.p.m.). Once the $\mathrm{OD}_{600}$ reached 1.0 (after about $3 \mathrm{~h}$ ), the shaker temperature was reduced to $22^{\circ} \mathrm{C}$, and $15 \mathrm{~min}$ later protein expression was induced with a final concentration of $0.2 \mathrm{mM}$ isopropyl $\beta$-D-1-thiogalactopyranoside. After overnight induction at $22^{\circ} \mathrm{C}$, cells were collected by centrifugation at $4,000 \mathrm{~g}$ for $15 \mathrm{~min}$ at $4{ }^{\circ} \mathrm{C}$ and stored at $-80^{\circ} \mathrm{C}$ until needed. Cultures for large-scale protein expression were $800 \mathrm{ml}$ in volume, while $15-\mathrm{ml}$ cultures were grown similarly to test protein expression in small scale.

For large-scale purification of PIP synthases, frozen cell pellets were resuspended in lysis buffer containing $20 \mathrm{mM}$ HEPES-NaOH (pH 7.5), $200 \mathrm{mM}$ $\mathrm{NaCl}, 20 \mathrm{mM} \mathrm{MgSO}_{4}, 10 \mu \mathrm{g} \mathrm{ml}^{-1}$ DNase I, $10 \mu \mathrm{g} \mathrm{ml}^{-1}$ RNase A, $1 \mathrm{mM}$ TCEP, $1 \mathrm{mM}$ phenylmethyl sulfonyl fluoride (PMSF) and Complete Mini EDTA-free protease inhibitor cocktail (Roche) used as described in the instructions. Cells were lysed with an Emulsiflex C3 homogenizer (Avestin). Lysate was solubilized for $1.5 \mathrm{~h}$ with $1 \%(w / v) n$-dodecyl- $\beta$-D-maltopyranoside (DDM, Anagrade, Affymetrix) in a volume of $\sim 40 \mathrm{ml}$ per cell pellet from $800 \mathrm{ml}$ culture ( $\sim 6 \mathrm{~g}$ cells). Insoluble material was then pelleted by ultracentrifugation at $134,000 \mathrm{~g}$ for $30 \mathrm{~min}$ at $4{ }^{\circ} \mathrm{C}$. Protein was purified from the supernatant by immobilized metal-affinity chromatography (Ni-NTA, Qiagen). The soluble fraction was incubated with pre-equilibrated Ni-NTA beads $(0.5 \mathrm{ml}$ for $40 \mathrm{ml}$ soluble fraction) for $2 \mathrm{~h}$. The beads were washed with 10 column volumes of $20 \mathrm{mM}$ HEPES-NaOH (pH 7.5), $200 \mathrm{mM} \mathrm{NaCl}, 0.1 \%(\mathrm{w} / \mathrm{v}) \mathrm{DDM}$ and $60 \mathrm{mM}$ imidazole $(\mathrm{pH} 7.5)$. The protein was then eluted from the beads with 5 column volumes of $20 \mathrm{mM}$ HEPES-NaOH (pH 7.5), $200 \mathrm{mM} \mathrm{NaCl}, 0.05 \%$ (w/v) DDM and $300 \mathrm{mM}$ imidazole (pH 7.5). Ni-NTA elutions were dialysed overnight in a Slide-A-Lyzer dialysis cassette (Thermo Scientific) at $4{ }^{\circ} \mathrm{C}$ in the presence of TEV protease $\left(150 \mu \mathrm{l}\right.$ at $\left.3 \mathrm{mg} \mathrm{ml}^{-1}\right)$ to cleave the decahistidine tag. The dialysis buffer consisted of $20 \mathrm{mM}$ HEPES$\mathrm{NaOH}$ (pH 7.0), $200 \mathrm{mM} \mathrm{NaCl}$ and $0.05 \%$ (w/v) DDM. The next day, the sample was removed from the dialysis cassette and purified again using washed Ni-NTA to remove TEV protease, cleaved decahistidine tags and any non-cleaved protein Flow-through containing purified cleaved protein was subjected to SEC using a Superose 12 column (GE Healthcare) in a buffer of $20 \mathrm{mM}$ HEPES-NaOH $(\mathrm{pH}$ 7.0), $200 \mathrm{mM} \mathrm{NaCl}, 0.025 \%$ (w/v) DDM and $1 \mathrm{mM}$ Tris(2-carboxyethyl)phosphine hydrochloride (TCEP-HCl). Protein eluted as a sharp monodisperse peak, as could be judged by monitoring A280. Approximately $0.75 \mathrm{mg}$ of purified protein could be obtained from an 800-ml bacterial culture.

Small-scale initial protein expression tests were performed similarly using $100 \mathrm{mg}$ quantities of cells from a $15-\mathrm{ml}$ culture. Lysis was performed using a tip sonicator $(3 \times 5$-s pulses with 5 -s cooling intervals between pulses), and purification proceeded until the first immobilized metal-affinity chromatography step, after which the Ni-NTA elutions were mixed with $6 \times$ SDS loading buffer and run on 12 or $14 \%$ SDS-PAGE gels to identify expressing PIP-synthase constructs.

For isolation of membranes, frozen cell pellets were resuspended in lysis buffer containing $20 \mathrm{mM}$ HEPES-NaOH (pH 7.5), $200 \mathrm{mM} \mathrm{NaCl}, 20 \mathrm{mM} \mathrm{MgSO}_{4}$, $10 \mu \mathrm{g} \mathrm{ml}^{-1}$ DNase I, $10 \mu \mathrm{g} \mathrm{ml}^{-1}$ RNase A, $1 \mathrm{mM}$ TCEP, $1 \mathrm{mM} \mathrm{PMSF}$ and Complete Mini EDTA-free protease inhibitor cocktail used as described in the instructions. Cells were lysed with an Emulsiflex C3 homogenizer (Avestin). The membrane fraction was pelleted by ultracentrifugation at $134,000 \mathrm{~g}$ for $30 \mathrm{~min}$ at $4{ }^{\circ} \mathrm{C}$. To remove water-soluble proteins, membranes were resuspended by homogenization in a high-salt buffer containing $20 \mathrm{mM}$ HEPES-NaOH $(\mathrm{pH} 7.5)$, $500 \mathrm{mM} \mathrm{NaCl}, 20 \mathrm{mM} \mathrm{MgSO}_{4}, 10 \mu \mathrm{g} \mathrm{ml}^{-1}$ DNase I, $10 \mu \mathrm{g} \mathrm{ml}^{-1} \mathrm{RNase} \mathrm{A}, 1 \mathrm{mM}$ TCEP, $1 \mathrm{mM}$ PMSF and Complete Mini EDTA-free protease inhibitor cocktail. The membrane fraction was pelleted once again by ultracentrifugation at $134,000 \mathrm{~g}$ for $30 \mathrm{~min}$ at $4^{\circ} \mathrm{C}$. Membranes were then resuspended by homogenization in storage buffer containing $20 \mathrm{mM}$ HEPES-NaOH (pH 7.5), $200 \mathrm{mM} \mathrm{NaCl}, 20 \mathrm{mM}$ $\mathrm{MgSO}_{4}$ and $1 \mathrm{mM}$ TCEP. If required, resuspended membranes were solubilized for $1.5 \mathrm{~h}$ with $1 \%(\mathrm{w} / \mathrm{v})$ DDM. Protein purification was carried out as described above.

Preparation of liposomes and proteoliposomes. E. coli polar lipid extract (Avanti) and phosphatdiylcholine (Avanti) were mixed in a 3:1 ratio (w/w) by dissolving in chloroform. Chloroform was removed under a stream of nitrogen gas to obtain a thin layer of dry lipids. Lipids were resuspended in buffer containing $100 \mathrm{mM}$ HEPES, pH 7.5 and $1.5 \%$ (w/v) $1-O-n$-Octyl- $\beta$-D-glucopyranoside 
(Anagrade, Affymetrix) and the detergent was removed by dialysis against 11 of $100 \mathrm{mM}$ HEPES, pH 7.5. The resulting liposomes were divided into aliquotes, frozen in liquid nitrogen and stored at $-80^{\circ} \mathrm{C}$. For protein incorporation into liposomes, the protocol used was adapted from Rigaud et al..$^{25}$. The concentration of thawed liposomes was adjusted to $10 \mathrm{mg} \mathrm{ml}^{-1}$ with $100 \mathrm{mM} \mathrm{HEPES,} \mathrm{pH} \mathrm{7.5;}$ $0.11 \%(\mathrm{w} / \mathrm{v})$ Triton X-100 was added to the liposome-containing solution and mixed by vortexing. Protein, purified as previously described, was then added in a ratio of 1:80 (0.125 $\mathrm{mg}$ protein to $10 \mathrm{mg}$ lipid). The mixture was incubated at room temperature with agitation for $15 \mathrm{~min}$. A unit of $60 \mathrm{mg}$ of pretreated and equilibrated Bio-Beads SM-2 (BioRad) were added to the mixture and incubated at room temperature for $1 \mathrm{~h}$ under constant agitation. An additional $60 \mathrm{mg}$ of Bio-Beads were then added to the mixture and incubated at room temperature for $1 \mathrm{~h}$ under constant agitation. Then, $120 \mathrm{mg}$ of Bio-Beads were added to the mixture and incubated overnight at $4{ }^{\circ} \mathrm{C}$ with under constant agitation, after which proteoliposomes were separated and removed from the Bio-Beads by careful pipetting. The concentration of proteoliposomes was adjusted by ultracentrifugation $\left(148,000 \mathrm{~g}\right.$ for $30 \mathrm{~min}$ at $\left.4{ }^{\circ} \mathrm{C}\right)$ and resuspension in the correct volume of buffer (100 mM HEPES, pH 7.5). Proteoliposomes were divided into aliquotes, flash frozen in liquid nitrogen and stored at $-80^{\circ} \mathrm{C}$.

Preparation of cell-free homogenates for functional assays. Frozen recombinant cells of $E$. coli expressing PIP-synthase constructs $(\sim 2 \mathrm{~g})$, grown as described above, were suspended in $5 \mathrm{ml}$ buffer A ( $50 \mathrm{mM}$ Tris- $\mathrm{HCl}, \mathrm{pH} 7.6,10 \mathrm{mM} \mathrm{MgCl}_{2}$ and $5 \mathrm{mM} \beta$-mercaptoethanol) and disrupted by sonication $(5 \times 60$-s pulses with 60-s cooling intervals between pulses). Cell debris and unbroken cells were separated by centrifugation $\left(10,000 \mathrm{~g}, 10 \mathrm{~min}, 4^{\circ} \mathrm{C}\right)$, and membrane fractions were obtained by centrifugation of the supernatant at $100,000 \mathrm{~g}$ for $2 \mathrm{~h}$ at $4{ }^{\circ} \mathrm{C}$. The membrane fractions were suspended in $0.5 \mathrm{ml}$ of buffer $\mathrm{A}$ and frozen at $-20^{\circ} \mathrm{C}$ until use.

Preparation of L-myo- $\left[{ }^{\mathbf{1 4}} \mathrm{C}\right]$ inositol-1-phosphate. L-myo- $\left[{ }^{14} \mathrm{C}\right]$ inositol-1phosphate was prepared from $\left[{ }^{14} \mathrm{C}(\mathrm{U})\right]$ glucose (Perkin Elmer Life Sciences) using hexokinase of Thermoproteus tenax and L-myo-inositol-1-phosphate synthase (IPS) of Archaeoglobus fulgidus. E. coli cells harbouring the hexokinase or the ips genes were grown in Luria-Bertani medium at $37^{\circ} \mathrm{C}$ supplemented with $100 \mu \mathrm{g} \mathrm{ml}{ }^{-1}$ ampicillin to an optical density of 0.5 at $600 \mathrm{~nm}$, and protein expression was induced for $4 \mathrm{~h}$ with $1 \mathrm{mM}$ isopropyl $\beta$-D-1-thiogalactopyranoside ${ }^{15}$. Partial purification of recombinant hexokinase and IPS was performed by heating the cell extracts for $30 \mathrm{~min}$ at 90 and $60^{\circ} \mathrm{C}$, respectively, followed by centrifugation to remove denatured proteins. The production of $\left[{ }^{14} \mathrm{C}\right]$ glucose-6-phosphate was carried out in a reaction mixture containing the recombinant hexokinase,

$\left[{ }^{14} \mathrm{C}(\mathrm{U})\right]$ glucose $(3.7 \mathrm{MBq}$ per $336 \mathrm{nmol}), 10 \mathrm{mM}$ glucose, $5 \mathrm{mM}$ ATP, $50 \mathrm{mM}$ Tris- $\mathrm{HCl}\left(\mathrm{pH} \mathrm{7.6)}\right.$ and $10 \mathrm{mM} \mathrm{MgCl}_{2}$. After $1 \mathrm{~h}$ of incubation at $70^{\circ} \mathrm{C}$, the reaction mixture was centrifuged $\left(10,000 \mathrm{~g}, 10 \mathrm{~min}, 4^{\circ} \mathrm{C}\right)$, and the resulting supernatant was added to a reaction mixture containing the recombinant IPS, $5 \mathrm{mM} \mathrm{NAD}^{+}$and $50 \mathrm{mM}$ Tris- $\mathrm{HCl}(\mathrm{pH} 7.6)$. After incubation at $85.5^{\circ} \mathrm{C}$ for $1 \mathrm{~h}$, and centrifugation $\left(10,000 \mathrm{~g}, 10 \mathrm{~min}, 4^{\circ} \mathrm{C}\right)$, the resulting supernatant was treated with activated charcoal to eliminate residual nucleotides, and then filtered through a $10-\mathrm{kDa}$ Omega Nanosep filter (Pall Life Sciences, Hampshire, UK) to remove proteins. The filtrate contained L-myo- $\left[{ }^{14} \mathrm{C}\right]$ inositol-1-phosphate, $\left[{ }^{14} \mathrm{C}\right]$ glucose-6-phosphate and $\left[{ }^{14} \mathrm{C}\right]$ glucose. L-myo- $\left[{ }^{14} \mathrm{C}\right]$ inositol-1-phosphate present in the preparation was quantified after thin-layer chromatography separation and used as a substrate for assays of PIP-synthase activity.

Measurement of PIP-synthase activity. The reaction mixtures (final volume, $200 \mu \mathrm{l})$ contained the membrane fraction $(200 \mu \mathrm{g}$ of total membrane protein as determined by the Bradford method) of E. coli expressing PIPS constructs, $6.5 \mu \mathrm{M}$ L-myo- $\left[{ }^{14} \mathrm{C}\right]$ inositol-1-phosphate, $161 \mu \mathrm{M}$ of cold inositol phosphate prepared as described above, $0.4 \mathrm{mM}$ CDP-dioleoylglycerol (Avanti Polar Lipids), $10 \mathrm{mM}$ $\mathrm{MgCl}_{2}, 10 \mathrm{mM} \beta$-mercaptoethanol, 1\% (w/v) 3-[(3-cholamidopropyl)dimethylammonio]-1-propanesulfonate (CHAPS) and $50 \mathrm{mM}$ Bicine buffer ( $\mathrm{pH} 8.0$ ). The reaction was started by the addition of the membrane fraction. The mixtures were incubated at $37^{\circ} \mathrm{C}$ during $1 \mathrm{~h}$ and reactions were stopped by addition of $1 \mathrm{ml}$ of $0.1 \mathrm{M} \mathrm{HCl}$ in methanol. The mixtures were transferred to glass tubes containing $1.5 \mathrm{ml} 0.1 \mathrm{M} \mathrm{HCl}$ in methanol and $2.5 \mathrm{ml} \mathrm{CHCl}_{3}$. The partition into aqueous and organic layers was carried out with addition of $2.15 \mathrm{ml} \mathrm{MgCl}_{2}$ (1 M, pH 2). The organic layer was removed and washed twice with $0.1 \mathrm{M} \mathrm{HCl}$, methanol/1 $\mathrm{M} \mathrm{MgCl}_{2}$ $(1: 0.8, \mathrm{v} / \mathrm{v})$. The radiolabelled product (in the organic layer) was quantified using a liquid scintillation counter (Beckman LS 6,500). To study the effect of $\mathrm{PO}_{4}^{-3}$ and $\mathrm{SO}_{4}^{-2}$ on PIP-synthase activity, different concentrations of each compound (ranging from 1 to $200 \mathrm{mM}$, in the form of $\mathrm{K}_{2} \mathrm{HPO}_{4}$ and $\mathrm{K}_{2} \mathrm{SO}_{4}$ ) were added to the reaction mixture containing $200 \mu \mathrm{g}$ of total membrane protein of $E$. coli expressing MtPIPS-WT, $6.5 \mu \mathrm{M} \mathrm{L}$-myo- $\left[{ }^{14} \mathrm{C}\right]$ inositol-1-phosphate, $161 \mu \mathrm{M}$ of cold inositol phosphate, $0.4 \mathrm{mM}$ CDP-dioleoylglycerol, $10 \mathrm{mM} \mathrm{MgCl}_{2}, 10 \mathrm{mM} \beta$-mercaptoethanol, $1 \%(\mathrm{w} / \mathrm{v})$ CHAPS and $50 \mathrm{mM}$ Bicine buffer ( $\mathrm{pH} 8.0)$. The reaction mixtures were incubated at $37^{\circ} \mathrm{C}$ for $1 \mathrm{~h}$ and the extraction and quantification of the radiolabelled product was assessed as mentioned above. These functional assays were performed in triplicate.
Assessment of $\boldsymbol{K}_{\mathbf{M}}$ of MtPIPS for inositol phosphate. The $K_{\mathrm{M}}$ of MtPIPS (WT, R195Q and P153V) was assessed in reaction mixtures (final volume, $200 \mu \mathrm{l}$ ) containing $2 \mathrm{mM}$ CDP-dioleoylglycerol, $10 \mathrm{mM} \mathrm{MgCl}_{2}, 10 \mathrm{mM} \beta$-mercaptoethanol, $1 \%(\mathrm{w} / \mathrm{v})$ CHAPS, $50 \mathrm{mM}$ Bicine buffer ( $\mathrm{pH} 8.0), 9 \mu \mathrm{M} \mathrm{L}-m y o-\left[{ }^{14} \mathrm{C}\right]$ inositol-1phosphate plus different concentrations of cold inositol phosphate (final concentrations of $38 \mu \mathrm{M}-1 \mathrm{mM}$ for WT and P153V, and $38 \mu \mathrm{M}-4 \mathrm{mM}$ for R195Q).

The mixtures were pre-incubated for $3 \mathrm{~min}$ at $37^{\circ} \mathrm{C}$ and the reactions initiated by addition of the membrane fraction of $E$. coli expressing MtPIPS ( $200 \mu \mathrm{g}$ of total membrane protein) and stopped at different time points by the addition of $1 \mathrm{ml}$ of $0.1 \mathrm{M} \mathrm{HCl}$ in methanol. The extraction and quantification of the radiolabelled product was performed as described above. These experiments were performed in duplicate.

Assessment of $\boldsymbol{K}_{\mathbf{M}}$ of $\boldsymbol{M t P I P S}$ for CDP-dioleoylglycerol. The $K_{\mathrm{M}}$ of MtPIPS (WT, R195Q and P153V) for CDP-DAG was performed in reaction mixtures (final volume, $200 \mu \mathrm{l}$ ) containing $1 \mathrm{mM}$ of inositol phosphate (from which $9 \mu \mathrm{M}$ was L-myo- $\left[{ }^{14} \mathrm{C}\right]$ inositol-1-phospate), $10 \mathrm{mM} \mathrm{MgCl} 2,10 \mathrm{mM} \beta$-mercaptoethanol, $1 \%(\mathrm{w} / \mathrm{v})$ CHAPS, $50 \mathrm{mM}$ Bicine buffer ( $\mathrm{pH} 8.0)$, plus different concentrations of CDP-dioleoylglycerol (ranging from 50 to $2,000 \mu \mathrm{M}$ ). The mixtures were pre-incubated for $3 \mathrm{~min}$ at $37^{\circ} \mathrm{C}$ and the reactions initiated by the addition of the membrane fraction of E. coli expressing MtPIPS ( $200 \mu \mathrm{g}$ of protein) and stopped at different time points by addition of $1 \mathrm{ml}$ of $0.1 \mathrm{M} \mathrm{HCl}$ in methanol. The extraction and quantification of the radiolabelled product was performed as described above. These experiments were performed in duplicate.

Binding assays with L-myo-[ $\left[{ }^{14} \mathrm{C}\right]$ inositol-1-phosphate. $\mathrm{L}-m y o-\left[{ }^{14} \mathrm{C}\right]$ inositol-1 phosphate-binding assays were carried out in reaction mixtures (final volume, $100 \mu \mathrm{l})$ containing MtPIPS (WT, D93N or R195Q) reconstituted in proteoliposomes $(9 \mu \mathrm{g}$ of protein), $2 \mathrm{mM} \mathrm{MgCl}, 40 \mu \mathrm{M}$ inositol phosphate (of which $16 \mu \mathrm{M}$ was L-myo- $\left[{ }^{14} \mathrm{C}\right]$ inositol-1-phospate) and $50 \mathrm{mM}$ Bicine buffer (pH 8.0). The mixtures were pre-incubated for $3 \mathrm{~min}$ at $37^{\circ} \mathrm{C}$ absent ligand, the reactions initiated by the addition of inositol phosphate and stopped after $10 \mathrm{~min}$. The binding assay mixtures were passed over HAWP 02500 filters (Millipore), and unbound $\mathrm{L}-m y o-\left[{ }^{14} \mathrm{C}\right]$ inositol-1-phosphate was separated from the bound by washing three times with $600 \mu \mathrm{l}$ of $50 \mathrm{mM}$ Bicine buffer (pH 8.0). Bound $\mathrm{L}-m y o-\left[{ }^{14} \mathrm{C}\right]$ inositol-1-phosphate was quantified by liquid scintillation counting. The effect of CDP-DAG on the binding of inositol phosphate to MtPIPS was investigated by pre-incorporating $200 \mu \mathrm{M}$ CDP-DAG in the proteoliposomes used in each reaction mixture. Assays and quantification of bound $\mathrm{L}-m y o-\left[{ }^{14} \mathrm{C}\right]$ inositol1-phosphate were performed as described above. Assays on empty liposomes to calculate background were also performed as described above for proteoliposomes. These binding assays were performed in triplicate.

Crystallization. Crystals were grown at room temperature $\left(22^{\circ} \mathrm{C}\right)$ in lipidic cubic phase, using as host lipid either monoolein alone (NuChek Prep) or a mixture of $2 \%$ CDP-dioleoylglycerol (Avanti Polar Lipids) and $98 \%$ monoolein by mass. The mixture of CDP-dioleoylglycerol and monoolein was prepared the day before it was needed, and involved dissolving CDP-dioleoylglycerol in chloroform, adding it to molten monoolein in the appropriate amount to generate a 2:98 ratio by mass, vortexing, and then evaporating the chloroform with argon gas first and then overnight in a vacuum desiccator. Protein from peak fractions from SEC was concentrated to $35-40 \mathrm{mg} \mathrm{ml}^{-1}$ (estimated by $A_{280 \mathrm{~nm}}$ ) for crystallization using a centrifugal concentrator (Millipore) with a $100 \mathrm{kDa}$ molecular weight cutoff. Concentrated protein was mixed with molten lipid in a 1:1.5 (w/w) ratio of protein:lipid using coupled syringes. A Mosquito LCP (TTP Labtech) robot was used to dispense a typical volume of $50-75 \mathrm{nl}$ of protein/lipid mixture onto a 96-well glass sandwich plate, which was covered with $750 \mathrm{nl}$ precipitant solution and sealed with a glass coverslip. Glass sandwich plates were stored in a $22-^{\circ} \mathrm{C}$ incubator. Crystals appeared after 1-2 days and grew to full size in about 1 week. Crystals grew in (a) 20\% (v/v) polyethylene glycol 400, 0.1 M MES (pH 6.7) and $0.2 \mathrm{M}$ lithium sulfate (RsPIPS- $\Delta 6 \mathrm{~N}$ ), and (b) $30 \%(\mathrm{v} / \mathrm{v})$ polyethylene glycol 300 , $0.1 \mathrm{M}$ MES pH 6.0, $0.1 \mathrm{M}$ sodium chloride and $0.1 \mathrm{M}$ magnesium chloride (RsPIPS-FL in 2\% CDP-DAG/98\% monoolein). A tungsten carbide glass cutter (Hampton Research) was used to cut and remove the glass coverslip, and crystals were collected using 20-100 $\mu \mathrm{m}$ MicroLoops and MicroMounts (MiTeGen). Crystals were flash cooled directly in liquid nitrogen without additional cryoprotection. RsPIPS- $\Delta 6 \mathrm{~N}$ crystallizes in space group P $2_{1} 2_{1} 2$, with unit cell parameters $(\AA) a=48.63, b=94.07, c=103.92$, with one protomer in the asymmetric unit, and diffraction to $2.5 \AA$. RsPIPS-FL crystallizes in space group $\mathrm{P} 2{ }_{1}$, with unit cell parameters ( $\AA$ ) $a=89.00, b=62.49, c=169.76, \beta=99.77^{\circ}$, with two dimers in the asymmetric unit, and diffraction to $3.6 \AA$

Data collection and structure determination. Diffraction data were collected on beamlines 24-ID-C and 24-ID-E at the Advanced Photon Source (Argonne, IL). The data were indexed, integrated, scaled and merged using $\mathrm{XDS}^{26}$ and AIMLESS $^{27}$. The structure of $R s$ PIPS- $\Delta 6 \mathrm{~N}$ was solved by molecular replacement using PHASER ${ }^{28}$, searching separately for the extramembrane and transmembrane domains of Af2299 (PDB ID 4O6M). The final data set includes data collected from four isomorphous crystals. After density modification using PARROT ${ }^{29}$, the model 
was manually corrected and completed using $\operatorname{Coot}^{30}$, and refined using the PHENIX crystallographic software package ${ }^{31}$, alternating between cycles of manual building in Coot and refinement in PHENIX. The final RsPIPS- $\Delta 6 \mathrm{~N}$ model has an $R_{\text {work }} / R_{\text {free }}$ of $0.2284 / 0.2520$. The structure of RsPIPS-FL was solved by molecular replacement using PHASER, searching separately for four copies each of the extramembrane and transmembrane domains from the structure of RsPIPS- $\Delta 6 \mathrm{~N}$. Density modification, including non-crystallographic averaging, was performed using PARROT, and the model was completed following the same protocol as for the structure of RsPIPS- $\Delta 6 \mathrm{~N}$, using the structure of RsPIPS- $\Delta 6 \mathrm{~N}$ as a reference model for the generation of restraints ${ }^{32}$, in addition to the application of noncrystallographic symmetry based torsion angle restraints and secondary structure restraints, giving a model with a final $R_{\text {work }} / R_{\text {free }}$ of $0.2801 / 0.2997$. All protein structure figures were prepared using UCSF Chimera ${ }^{33}$. In the structure of RsPIPS$\Delta 6 \mathrm{~N}$, many partially ordered lipid molecules were readily apparent in the electron density map (Supplementary Fig. 8). As no head groups or identifying features were discernable in the density, all lipids were modelled as isolated alkyl chains and assigned the residue code UNL, the PDB-recommended code for all unidentified ligands.

\section{References}

1. Umesiri, F. E., Sanki, A. K., Boucau, J., Ronning, D. R. \& Sucheck, S. J. Recent advances toward the inhibition of mAG and LAM synthesis in Mycobacterium tuberculosis. Med. Res. Rev. 30, 290-326 (2010).

2. Angala, S. K., Belardinelli, J. M., Huc-Claustre, E., Wheat, W. H. \& Jackson, M. The cell envelope glycoconjugates of Mycobacterium tuberculosis. Crit. Rev. Biochem. Mol. Biol. 49, 1-39 (2014).

3. Fischl, A. S. \& Carman, G. M. Phosphatidylinositol biosynthesis in Saccharomyces cerevisiae: purification and properties of microsome-associated phosphatidylinositol synthase. J. Bacteriol. 154, 304-311 (1983).

4. Morii, H., Ogawa, M., Fukuda, K., Taniguchi, H. \& Koga, Y. A revised biosynthetic pathway for phosphatidylinositol in Mycobacteria. J. Biochem. 148, 593-602 (2010).

5. Morii, H., Kiyonari, S., Ishino, Y. \& Koga, Y. A novel biosynthetic pathway of archaetidyl-myo-inositol via archaetidyl-myo-inositol phosphate from CDP-archaeol and D-glucose 6-phosphate in methanoarchaeon Methanothermobacter thermautotrophicus cells. J. Biol. Chem. 284, 30766-30774 (2009)

6. Carman, G. M. \& Belunis, C. J. Phosphatidylglycerophosphate synthase activity in Saccharomyces cerevisiae. Can. J. Microbiol. 29, 1452-1457 (1983).

7. Bae-Lee, M. S. \& Carman, G. M. Phosphatidylserine synthesis in Saccharomyces cerevisiae. Purification and characterization of membraneassociated phosphatidylserine synthase. J. Biol. Chem. 259, 10857-10862 (1984).

8. Sciara, G. et al. Structural basis for catalysis in a CDP-alcohol phosphotransferase. Nat. Commun. 5, 4068 (2014).

9. Nogly, P. et al. X-ray structure of a CDP-alcohol phosphatidyltransferase membrane enzyme and insights into its catalytic mechanism. Nat. Commun. 5, 4169 (2014).

10. Gonçalves, L. G. et al. Evolution of the biosynthesis of di-myo-inositol phosphate, a marker of adaptation to hot marine environments. Environ. Microbiol. 14, 691-701 (2011).

11. Jackson, M., Crick, D. C. \& Brennan, P. J. Phosphatidylinositol is an essential phospholipid of mycobacteria. J. Biol. Chem. 275, 30092-30099 (2000).

12. Salman, M., Lonsdale, J. T., Besra, G. S. \& Brennan, P. J. Phosphatidylinositol synthesis in mycobacteria. Biochim. Biophys. Acta 1436, 437-450 (1999).

13. Morii, H. et al. Studies of inositol 1-phosphate analogues as inhibitors of the phosphatidylinositol phosphate synthase in mycobacteria. J. Biochem. 153, 257-266 (2013).

14. Brito, J. A., Borges, N., Vonrhein, C., Santos, H. \& Archer, M. Crystal structure of Archaeoglobus fulgidus CTP:inositol-1-phosphate cytidylyltransferase, a key enzyme for di-myo-inositol-phosphate synthesis in (hyper)thermophiles. J. Bacteriol. 193, 2177-2185 (2011).

15. Rodrigues, M. V. et al. Bifunctional CTP:inositol-1-phosphate cytidylyltransferase/CDP-inositol:inositol-1-phosphate transferase, the key enzyme for di-myo-inositol-phosphate synthesis in several (hyper)thermophiles. J. Bacteriol. 189, 5405-5412 (2007).

16. Caffrey, M. Crystallizing membrane proteins for structure determination: use of lipidic mesophases. Annu. Rev. Biophys. 38, 29-51 (2009).

17. Fryer, J. L. \& Sanders, J. E. Bacterial kidney disease of salmonid fish. Annu. Rev. Microbiol. 35, 273-298 (1981)

18. Williams, J. G. \& McMaster, C. R. Scanning alanine mutagenesis of the CDP-alcohol phosphotransferase motif of Saccharomyces cerevisiae cholinephosphotransferase. J. Biol. Chem. 273, 13482-13487 (1998).
19. Chun, E. et al. Fusion partner toolchest for the stabilization and crystallization of G protein-coupled receptors. Structure 20, 967-976 (2012).

20. Henneberry, A. L., Wright, M. M. \& McMaster, C. R. The major sites of cellular phospholipid synthesis and molecular determinants of fatty acid and lipid head group specificity. Mol. Biol. Cell 13, 3148-3161 (2002).

21. Dutt, A. \& Dowhan, W. Purification and characterization of a membraneassociated phosphatidylserine synthase from Bacillus licheniformis. Biochemistry 24, 1073-1079 (1985).

22. Hirabayashi, T., Larson, T. J. \& Dowhan, W. Membrane-associated phosphatidylglycerophosphate synthetase from Escherichia coli: purification by substrate affinity chromatography on cytidine 5'-diphospho-1,2-diacyl-snglycerol sepharose. Biochemistry 15, 5205-5211 (1976).

23. Aktas, M. et al. Enzymatic properties and substrate specificity of a bacterial phosphatidylcholine synthase. FEBS J. 281, 3523-3541 (2014).

24. Gibson, D. G. et al. Enzymatic assembly of DNA molecules up to several hundred kilobases. Nat. Methods 6, 343-345 (2009).

25. Rigaud, J. L., Pitard, B. \& Levy, D. Reconstitution of membrane proteins into liposomes: application to energy-transducing membrane proteins. Biochim. Biophys. Acta 1231, 223-246 (1995).

26. Kabsch, W. XDS. Acta Crystallogr. D Biol. Crystallogr. 66, 125-132 (2010).

27. Evans, P. R. \& Murshudov, G. N. How good are my data and what is the resolution? Acta Crystallogr. D Biol. Crystallogr. 69, 1204-1214 (2013).

28. Mccoy, A. J. et al. Phaser crystallographic software. J. Appl. Crystallogr. 40, 658-674 (2007).

29. Cowtan, K. Recent developments in classical density modification. Acta Crystallogr. D Biol. Crystallogr. 66, 470-478 (2010).

30. Emsley, P., Lohkamp, B., Scott, W. G. \& Cowtan, K. Features and development of Coot. Acta Crystallogr. D Biol. Crystallogr. 66, 486-501 (2010).

31. Adams, P. D. et al. PHENIX: a comprehensive Python-based system for macromolecular structure solution. Acta Crystallogr. D Biol. Crystallogr. 66 , 213-221 (2010).

32. Headd, J. J. et al. Use of knowledge-based restraints in phenix.refine to improve macromolecular refinement at low resolution. Acta Crystallogr. D Biol. Crystallogr. 68, 381-390 (2012).

33. Pettersen, E. F. et al. UCSF Chimera-a visualization system for exploratory research and analysis. J. Comput. Chem. 25, 1605-1612 (2004).

34. Kyte, J. \& Doolittle, R. F. A simple method for displaying the hydropathic character of a protein. J. Mol. Biol. 157, 105-132 (1982).

35. Voss, N. R. \& Gerstein, M. 3V: cavity, channel and cleft volume calculator and extractor. Nucleic Acids Res. 38, W555-W562 (2010).

36. Kelley, L. A. \& Sternberg, M. J. E. Protein structure prediction on the Web: a case study using the Phyre server. Nat. Protoc. 4, 363-371 (2009).

\section{Acknowledgements}

Crystallographic data for this study were measured at the NE-CAT beamlines 24-ID-C and E (supported by NIH-NIGMS grant P41 GM103403) at the Advanced Photon Source. This work was supported by an NIH-NIGMS initiative to the New York Consortium on Membrane Protein Structure (NYCOMPS; U54 GM095315), by NIH-NIGMS grant R01 GM111980 and by Fundação para a Ciência e a Tecnologia, POCTI, Portugal, PTDC/BBB-BEP/2532/2012 and MOSTMICRO, UID/CBQ/04612/ 2013. The access to the National NMR Facility was supported by RECI/BBB-BQB/0230/ 2012. We thank Brian Kloss for initial help with the expression constructs and Leora Hamberger for her assistance running the Mancia Lab.

\section{Author contributions}

O.B.C., D.T. and F.M. designed the constructs; D.T. and M.B.D. expressed and purified the protein, and generated mutants; M.K. assisted in protein purification and crystallization; D.T. produced diffraction quality crystals; O.B.C. and D.T. screened crystals and collected the diffraction data; S.B. and K.R.R. assisted with data collection and processing; O.B.C. determined the structures and refined the models; C.D.J., H.S., O.B.C., M.D.B. and F.M. planned the functional experiments; C.D.J. performed the functional experiments; O.B.C., C.D.J., L.S., W.A.H., H.S. and F.M. analysed the data and wrote the manuscript; F.M. coordinated the project.

\section{Additional information}

Accession codes: Coordinates and structure factors have been deposited in the Protein Data Bank under the accession codes 5D91 (RsPIPS- $\Delta 6 \mathrm{~N}$ ) and 5D92 (RsPIPS-FL).

Supplementary Information accompanies this paper at http://www.nature.com/ naturecommunications

Competing financial interests: The authors declare no competing financial interests. 
Reprints and permission information is available online at http://npg.nature.com/ reprintsandpermissions/

How to cite this article: Clarke, O. B. et al. Structural basis for phosphatidylinositol-phosphate biosynthesis. Nat. Commun. 6:8505 doi: 10.1038/ncomms9505 (2015). (c) (i) This work is licensed under a Creative Commons Attribution 4.0 International License. The images or other third party material in this article are included in the article's Creative Commons license, unless indicated otherwise in the credit line; if the material is not included under the Creative Commons license, users will need to obtain permission from the license holder to reproduce the material. To view a copy of this license, visit http://creativecommons.org/licenses/by/4.0/ 